\title{
Equatorial Observations made at the U. S. Naval Observatory.
} (Communicated by Rear Admiral C. H. Davis, Superintendent.)

End of the Eclipse of the Sun, Sept. 28, 1875.

Wash. m. t. $19^{\mathrm{h}} 4^{\mathrm{m}} 44^{\mathrm{s}} 7^{\mathrm{m}} \pm 5^{\mathrm{s}}$ 19426.6
Power Observer 132 A. Hall

40 E. S. Holden Uncertain by several seconds. Contact noted at $21^{\mathrm{s}}$ but seconds counted till $31^{\mathrm{s}}$, when limb was seen round without doubt.

Occultations of Saturn, Aug. 6 and Sept. 2, 1876.

Immersion Aug. 6.

Wash. m. t.

First contact with Ball

$$
\text { , Ring }
$$

$10^{\mathrm{h}} 33^{\mathrm{m}} 21^{\mathrm{s}} 0$

$1033 \quad 32.7$

Disapp. opening on following side10 $34 \quad 5.7$ npreceding $\gg 1035 \quad 7.6$

Second contact with Ball 103532.8

Emersion Aug. 6.

Middel of Ring

105622.2 :

Third contact with Ball

Middel of Ball

Fourth contact with Ball

Last-contact with Ring

Immersion Aug. 6.

First contact with Ball

105725.5 :

$\begin{array}{lll}10 & 58 & 49.1\end{array}$

$\begin{array}{lll}11 & 0 & 13.4\end{array}$

$\begin{array}{lll}11 & 1 & 14.3\end{array}$

103314.0

Second contact with Ball

103528.0

Emersion Aug. 6.

First edge of Ring

105613.1

Fourth contact with Ball

Second edge of Ring

$\begin{array}{lll}11 & 0 & 15.9\end{array}$

$\begin{array}{lll}11 & 1 & 20.0\end{array}$
Wash. m. t. Fourth contact with Ball $11^{\mathrm{h}} 0^{\mathrm{m}} 23^{\mathrm{s}} 0$

A. Hall

y

$\%$

$\eta$

ก

A. Hall

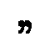

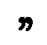

\%

n

E. Frisby

)

E. Frisby

n

ท

Last $\quad n \quad$ N King $11 \quad 114.9$ Immersion Sept. 2.

First contact with Ball

Middle of Ball

Second contact with Ball

Last edge of Ring I

First edge of Ring contact with Ball

Second $\gg, n$

Last edge of Ring

Immersion Aug. 6.

First contact with Ball $1032 \mathbf{5 5 . 0}$

Second , $\gg \quad 103510.2$

Emersion Aug. 6.

Third contact with Ball 105739.5

W. Harkness

》

W. Harkness
Remarks. The occultations of Saturn were observed by Prof. Hall with the 26inch Refractor, power 400: by Mr. Frisby with the $91 / 2$ inch Equatorial, on Aug. 6 with power 202, and on Sept. 2 with power 132; and by Prof. Harkness with his own telescope having an objective of 3inches and a magnifying power of 133. At immersion on Aug. 6 the images were poor; but at emersion, and on Sept. 2 the images were good.

No distortion of the ball or ring of the planet was noticed by any of the observers.

15. Sept. 1876.

Circular Orbit of $\xi$ Librae (= Scorpii).

(Read before the Royal Irish Academy.)

Node $=10^{\circ} 51^{\prime}$, Inclination $=72^{027}$, Period $=95$ years.

Least Distance 0"38 in 1859.62. Greatest Distance $1 " 25$ in 1883.37.

Markree, 20. September 1876.

W. Doberck. 